Info Artikel Diterima Januari 2021

Disetujui Maret 2021

Dipublikasikan April 2021

\title{
PERAN WANITA PETERNAK ITIK DALAM MEMBANTU \\ PENDAPATAN KELUARGA DI DESA ASAM PEUTIK KECAMATAN LANGSA LAMA KOTA LANGSA
}

\section{THE ROLE OF WOMAN DUCK BREEDER IN HELPING FAMILY INCOME IN ASAM PEUTIK VILLAGE LANGSA LAMA DISTRICT LANGSA CITY}

\author{
Kiagus Muhammad Zain Basriwijaya ${ }^{1}$, Fiddini Alham, Faoeza Hafiz Saragih \\ Prodi Agribisnis Fakultas Pertanian Universitas Samudra \\ Email 1: zainkiagus@gmail.com
}

\begin{abstract}
This research aims to analyse the role of female duck breeders in supporting family income in Asam Peutik Village, Langsa Lama District, Langsa City. The study is based on the fact that the number of poor people in Indonesia is still categorised as high (25.14 million people). Such condition encourages every member of the family, especially woman to work and take a role in improving family income. The method used in this research was survey method while the sampling was administered using simple random sampling. The analysis instruments were the outpouring of working time, analysis of family income, and the income contribution of female duck breeders. The results of the study showed that the average domestic working time of female duck breeders for cooking and washing was the same constituting of 1.17 hours/day, while the highest amount of working time was spent on child care activities, which was 2.71 hours/day. The average time spent on working to earn a living was 6.43 hours/day with percentage of $26.79 \%$. The highest average working time spent on social activities of female duck farmers in Asam Peutik Village was for religious assembly activities, namely 0.67 hour. The total family income of female duck breeders in Asam Peutik Village was Rp. 3,642,857/month. The highest average income level was obtained from the wife's income, constituting Rp. 2,247,619,-/month and the lowest was obtained from the other source of income, namely Rp. 114.286,-/month. The contribution of female duck breeders on family income in Asam Peutik village was classified as high, accounting for $63.28 \%$, which was greater than the contribution of husband's income accounting only for $33.22 \%$.
\end{abstract}

Kata Kunci: Poverty, Women, Income, Breeder, Duck.

\begin{abstract}
ABSTRAK
Penelitian ini bertujuan untuk menganalisis peran wanita peternak itik dalam membantu pendapatan keluarga di Desa Peutik Kecamatan Langsa Lama Kota Langsa. Hal ini dilatarbelakangi oleh jumlah penduduk miskin Indonesia masih dikategorikan tinggi (25,14 juta penduduk). Hal ini yang menjadi dorongan
\end{abstract}


hidup untuk setiap anggota keluarga bekerja terutama wanita ikut berperan dalam meningkatkan pendapatan keluarga. Metode penelitian yang digunakan dalam penelitian ini adalah metode survey, pengambilan sampel dilakukan secara simple random sampling. Alat analisis yang digunakan adalah curahan waktu kerja, analisis pendapatan keluarga, serta kontribusi pendapatan wanita peternak itik. Dari hasil penelitian dapat disimpulkan rata-rata curahan waktu kerja domestik wanita Peternak Itik untuk kegiatan memasak dan mencuci sama yaitu sebesar 1,17 jam/hari sementara curahan waktu kerja tertinggi adalah pada kegiatan mengurus anak yaitu sebesar 2,71 jam/hari. Rata-rata curahan waktu kerja mencari nafkah adalah sebesar 6,43 jam/hari dengan persentase sebesar 26,79\%. Rata-rata curahan waktu kerja kegiatan sosial wanita peternak itik di Desa Asam Peutik tertinggi pada kegiatan pengajian yaitu sebesar 0,67 jam. Total pendapatan keluarga wanita peternak itik di Desa Asam Peutik adalah sebesar Rp.3.642.857,/bulan. Rata-rata tingkat pendapatan tertinggi diperoleh dari pendapatan istri yaitu sebesar Rp. 2.247.619,-/bulan dan terendah diperoleh dari pendapatan sumber lain yaitu sebesar Rp. 114.286,-/bulan. Kontribusi pendapatan wanita Peternak Itik di Asam Peutik terhadap pendapatan keluarga adalah tergolong tinggi yakni sebesar 63,28 \% lebih besar dibandingkan kontribusi pendapatan suami yaitu sebesar $33,22 \%$.

\section{Kata Kunci: Itik, Kemiskinan, Pendapatan, Peternak, Wanita.}

\section{PENDAHULUAN}

Badan Pusat Statistik Aceh merilis jumlah penduduk miskin di Aceh pada Maret 2019 mencapai 819 ribu jiwa atau 15,32 persen. Persentase tersebut menunjukkan bahwa Aceh termasuk provinsi termiskin di Pulau Sumatera. Banyaknya jumlah keluarga miskin di Aceh membuat para wanita turut serta dalam menambah pendapatan keluarga. Keterlibatan perempuan dalam aktivitas sosial dan ekonomi di ranah publik tersebut dapat memberikan kontribusi yang sangat besar terhadap perubahan kedudukan sosialnya dirumah tangga. Di Asam Peutik, Langsa Kota, Kota Langsa para wanita memiliki peran ganda dengan beternak itik di Desa Asam Peutik dan bekerja mengurus rumah. Kontribusi Peternak Itik wanita dapat dilihat dari proporsi pendapatan pekerja wanita terhadap pendapatan keluarga. Bekerja sebagai Peternak Itik di pasar tradisional tidak membutuhkan modal yang besar dan persyaratan yang khusus, sehingga banyak wanita yang menjadi pedagang kaki lima (PKL) atau pengecer.

Seperti halnya penelitian Lutviani, dkk (2020) tenaga kerja wanita pemetik teh di PT Pagilaran Desa Keteleng Kecamatan Blado Kabupaten Batang, dimana alokasi waktu mencari nafkah menempati posisi pertama dibandingkan dengan kegiatan lainnya. Adapun kontribusi pendapatan tenaga kerja wanita pemetik teh, dapat menyumbang sebesar 32,8 persen terhadap pendapatan keluarganya. Dari curahan tenaga kerja ibu rumahtangga secara umum, dapat dikatakan bahwa perempuan bisa bekerja untuk mencari nafkah tambahan dalam memenuhi kebutuhan sehari-hari, curahan tenaga kerja ibu rumah tangga ini tidak hanya pada pekerjaan sebagai Peternak Itikan, disamping itu perempuan juga mengurus rumah tangga dan aktivitas-aktivitas lainnya. 


\section{BAHAN DAN METODE}

Metode dalam penelitian ini adalah metode survei digunakan untuk mendapatkan data dari tempat tertentu yang alamiah bukan buatan, tetapi peneliti melakukan perlakuan dalam pengumpulan data, misalnya dengan mengedarkan kuesioner, test, wawancara terstruktur dan sebagainya. Penentuan lokasi penelitian dilakukan secara sengaja (Purposive Sampling). Objek dari penelitian ini adalah wanita Peternak Itik Desa asam Peutik Kecamatan Langsa Lama Kota Langsa. Ruang lingkup penelitian ini yaitu mengenai peranan wanita Peternak Itik dalam meningkatkan pendapatan keluarga di Asam Peutik Kecamatan Langsa Kota, Kota Langsa. Pengambilan sampel dengan menggunakan metode Simple Random Sampling dengan teknik pengambilan secara acak. Wiratha (2006) mengemukakan dalam sampel random sederhana, anggota populasi tidak di pilah-pilah atau starata terlebih dahulu. Populasi dipilih secara random (acak), peneliti langsung mengacak untuk ukuran sampel yang diinginkan, jumlah populasi wanita Peternak Itik Asam Peutik Kecamatan Langsa kota, Kota Langsa diambil dari kantor Disperindag Kota Langsa saat peneliti melakukan pra survei di desa tersebut. Jumlah populasi wanita Peternak Itik yakni 118 orang. Penentuan sampel dilakukan menggunakan rumus slovin. Berdasarkan perhitungan, sampel yang menjadi responden dalam penelitian ini di sesuaikan menjadi sebanyak 21 orang atau sekitar $20 \%$ dari seluruh total wanita Peternak Itik Asam Peutik Kecamatan Langsa kota, Kota Langsa. Teknik pengumpulan data terbagi atsa dua tahap. Tahap pertama eksplorasi data sekunder, yang diperoleh dari berbagai instansi (Disperindag) yang berhubungan dengan penelitian ini. Tahap kedua pengumpulan data primer yang diperoleh dengan melakukan penelitian berupa wawancara mendalam dengan informasi suami dan istri Peternak Itik, baik secara individual maupun bersamaan dengan menggunakan daftar pertanyaan (kuisioner) yang telah dipersiapkan. Metode analisis data dalam penelitian ini antara lain:

\section{a. Curahan Waktu Kerja}

Menurut Gumilar (2005), curahan waktu kerja yang dilakukan oleh wanita Peternak Itik untuk kegiatan mencari nafkah diukur dengan menggunakan rumus:

$$
\text { cWKwnf }=\frac{\text { CWKwnf }}{\text { WKwnf }+ \text { WKwrt }+ \text { WKsos }} \times 100 \% \ldots \ldots \ldots \ldots \ldots
$$

\footnotetext{
Keterangan :

CWKwnf : Curahan waktu kerja perempuan untuk mencari nafkah WKwnf: Waktu kerja untuk mencari nafkah

WKwrt : Waktu kerja perempuan untuk kegiatan rumah tangga

WKsos : Waktu kerja perempuan untuk kegiatan sosial
}

\section{b. Analisis Pendapatan Keluarga}

Pendapatan rumah tangga berasal dari tiga sumber, yaitu dari suami, istri dan sumber lainnya. Menurut Mardiana (2004) pendapatan rumah tangga dapat dihitung dengan persamaan :

$$
I t=I m+I f+I o
$$


Keterangan :

It $\quad=$ Pendapatan rumah tangga $(\mathrm{Rp} / \mathrm{bln})$

$\mathrm{Im} \quad=$ Pendapatan suami $(\mathrm{Rp} / \mathrm{bln})$

If $\quad=$ Pendapatan istri $(\mathrm{Rp} / \mathrm{bln})$

Io $\quad=$ Pendapatan dari sumber lain $(\mathrm{Rp} / \mathrm{bln})$

\section{c. Kontribusi Pendapatan Wanita Peternak Itik}

Kontribusi pendapatan wanita Peternak Itik digunakan untuk mengetahui seberapa besar kontribusi pendapatan wanita Peternak Itik terhadap pendapatan keluarga (Gumilar, 2005) dapat dihitung dengan persamaan:

$K=\frac{I f}{I f+I m+I o} \times 100 \%$

Keterangan:

$\mathrm{K}=$ Kontribusi mutlak pendapatan wanita (\%)

$\mathrm{Im} \quad=$ Pendapatan suami $(\mathrm{Rp} / \mathrm{bln})$

If $\quad=$ Pendapatan istri $(\mathrm{Rp} / \mathrm{bln})$

Io $\quad=$ Pendapatan dari sumber lain $(\mathrm{Rp} / \mathrm{bln})$

\section{d. Pengujian Hipotesis}

Untuk menguji hipotesis yang menyatakan bagaimana peran wanita Peternak Itik dalam peningkatan kesejahteraan keluarga serta kontribusi pendapatan wanita Peternak Itik, menurut Handayani dalam Gusmaniar (2013), digunakan rumus sebagai berikut:

$$
\mathrm{P}=\frac{\mathrm{I}}{\mathrm{Pt}} \mathrm{x} 100 \% \ldots \ldots \ldots \ldots \ldots \ldots
$$

Keterangan

$\mathrm{P} \quad=$ Besarnya Sumbangan Pendapatan Wanita Peternak Itik (\%)

I $\quad=$ Pendapatan Wanita Peternak Itik $(\mathrm{Rp} / \mathrm{bln})$

$\mathrm{Pt} \quad=$ Total Pendapatan Keluarga Peternak Itik (Rp/bln)

Dengan Kriteria :

a. $0 \%-25 \%=$ tergolong rendah

b. $26 \%-50 \%=$ tergolong sedang

c. $51 \%-100 \%=$ tergolong tinggi

\section{HASIL DAN PEMBAHASAN}

\section{Curahan Waktu Kerja Untuk Kegiatan Domestik}

Rata-rata curahan waktu kerja wanita Peternak Itik untuk kegiatan domestik dapat lebih jelas dilihat pada Tabel 1. Berdasarkan Tabel 1 rata-rata curahan waktu kerja domestik wanita Peternak Itik untuk kegiatan memasak dan mencuci sama yaitu sebesar 1,17 jam/hari sementara curahan waktu kerja 
tertinggi adalah pada kegiatan mengurus anak yaitu sebesar 2,71 jam/hari. Jumlah curahan waktu kerja domestik wanita Peternak Itik pada kegiatan domestik adalah sebesar 6,26 jam/hari atau sebesar 26,09\% dari 24 jam kegiatan yang dilakukan oleh wanita Peternak Itik. Untuk curahan waktu kerja pada kegiatan domestik tertinggi yaitu pada kegiatan mengurus anak diikuti kegiatan membersihkan rumah, menyuci dan paling terendah adalah memasak. Kegiatan mengurus anak dimulai dari sebelum melakukan kegiatan mencari nafkah pada pagi hari dan setelah pulang. Sementara kegiatan memasak adalah kegiatan yang dilakukan sebelum kegiatan mencari nafkah dilakukan. Untuk kegiatan menyuci biasanya dilakukan tiga kali dalam satu minggu.

Tabel 1. Rata-rata Curahan Waktu Kerja Domestik Wanita Peternak Itik di Desa Asam Peutik, Kecamatan Langsa Kota, Kota Langsa, 2020.

\begin{tabular}{|c|c|c|c|c|c|c|c|}
\hline \multirow[t]{2}{*}{ No } & \multirow{2}{*}{$\begin{array}{l}\text { Jenis } \\
\text { Pekerjaan }\end{array}$} & \multicolumn{4}{|c|}{ Curahan Waktu Domestik (Jam/Hari) } & \multirow{2}{*}{$\begin{array}{l}\text { Jumlah } \\
\text { (Jam/Hari) }\end{array}$} & \multirow{2}{*}{$\begin{array}{l}\% \\
(24 \\
\text { Jam) }\end{array}$} \\
\hline & & Memasak & Mencuci & $\begin{array}{l}\text { Bersihkan } \\
\text { Rumah }\end{array}$ & $\begin{array}{l}\text { Mengurus } \\
\text { Anak }\end{array}$ & & \\
\hline 1. & $\begin{array}{l}\text { Wanita } \\
\text { Peternak Itik }\end{array}$ & 1,17 & 1,17 & 1,21 & 2,71 & 6,26 & 26,09 \\
\hline
\end{tabular}

Sumber : Lampiran 3.

\section{Curahan Waktu Kerja Mencari Nafkah}

Rata-rata curahan waktu kerja mencari nafkah wanita Peternak Itik dapat lebih jelas dilihat pada Tabel 2 .

Tabel 2. Rata-rata Curahan Waktu Kerja Mencari Nafkah Wanita Peternak Itik di Pasar Asam Peutik, Kecamatan Langsa Kota, Kota Langsa, 2020.

\begin{tabular}{llll}
\hline No & Jenis Pekerjaan & $\begin{array}{l}\text { Curahan Waktu } \\
\text { Mencari Nafkah }\end{array}$ & (24 Jam) \\
\hline 1 & Wanita Peternak Itik & 6,43 & 26,79 \\
\hline
\end{tabular}

Sumber: Data Primer (diolah).

Berdasarkan Tabel 2 rata-rata curahan waktu kerja mencari nafkah adalah sebesar 6,43 jam/hari dengan persentase sebesar 26,79\%. Kegiatan ekonomi yang dilakukan wanita Peternak Itik di Desa Asam Peutik adalah beternak itik dengan tujuan membantu perekonomian keluarga. Curahan waktu kerja yang curahkan untuk kegiatan mencari nafkah adalah sebesar 6,43 jam/ hari. Kegiatan beternak itik di Asam Peutik dimulai sejak pukul 4.30 sampai dengan pukul 10.00 pagi. Sayuran yang diperoleh wanita Peternak Itik di Desa Asam Peutik diperoleh dari pedagang pengumpul yang membeli langsung. Peternak Itik yang membeli langsung berasal dari daerah setempat.

\section{Curahan Waktu Kerja Kegiatan Sosial}

Kegiatan sosial wanita Peternak Itik di Asam Peutik meliputi kegiatan PKK, pengajian, dan posyandu. Rata-rata curahan waktu kerja kegiatan sosial wanita Peternak Itik di Desa Asam Peutik dapat lebih jelas dilihat pada Tabel 3. 
Tabel 3. Rata-rata Curahan Waktu Kerja Kegiatan Sosial Wanita Peternak Itik di Desa Asam Peutik, Kecamatan Langsa Kota, Kota Langsa, 2020.

\begin{tabular}{|c|c|c|c|c|c|c|}
\hline \multirow[t]{2}{*}{ No } & \multirow{2}{*}{$\begin{array}{l}\text { Jenis } \\
\text { Pekerjaan }\end{array}$} & \multicolumn{3}{|c|}{ Curahan Waktu Sosial (Jam) } & \multirow{2}{*}{$\begin{array}{l}\text { Jumlah } \\
\text { (Jam/Hari) }\end{array}$} & \multirow{2}{*}{$\begin{array}{l}\%(24 \\
\text { Jam) }\end{array}$} \\
\hline & & PKK & Pengajian & Posyandu & & \\
\hline 1. & $\begin{array}{l}\text { Wanita } \\
\text { Peternak } \\
\text { Itik }\end{array}$ & 0,38 & 0,67 & 0,52 & 1,57 & 6,55 \\
\hline
\end{tabular}

Sumber: Data Primer (diolah)

Berdasarkan Tabel 3 rata-rata curahan waktu kerja kegiatan sosial wanita Peternak Itik di Desa Asam Peutik tertinggi yaitu pada kegiatan PKK yaitu sebesar 0,38 jam sementara tertinggi pada kegiatan pengajian yaitu sebesar 0,67 jam. Jumlah jam keseluruhan rata-rata curahan waktu kerja kegiatan sosial wanita Peternak Itik di pasar Gamapong Blang adalah sebesar 1,57 jam dengan persentase sebesar $6,55 \%$.

Kegiatan sosial bertujuan mempererat tali silaturahmi sesama anggota masyarakat di Desa. Meskipun wanita Peternak Itik di Desa Asam Peutik sudah penuh dengan kegiatan domestik dan mencari nafkah, wanita Peternak Itik di Desa Asam Peutik juga meluangkan waktunya untuk kegiatan-kegiatan sosial di Desa. Rata-rata curahan waktu kerja sosial tertinggi adalah pada kegiatan pengajian yaitu sebesar 0,67 jam. Pengajian dan kegiatan PKK dilakukan dalam kurun waktu satu minggu sekali sementara posyandu dilakukan dalam tiga bulan satu kali. Kegian PKK merupakan kegiatan yang paling sedikit diminati oleh wanita Peternak Itik di Desa Asam Peutik mengingat kegiatan PKK tidak terlalu dibutuhkan oleh para wanita Peternak Itik di Desa Asam Peutik. Kegiatan sosial ini berperan sebagai sarana silaturahmi di tengah-tengah kegiatan wanita Peternak Itik. Selain itu, kegiatan sosial juga dapat menambah wawasan pemikiran wanita Peternak Itik menjadi lebih dinamis dan inovatif.

\section{Akumulasi Curahan Waktu Kerja Wanita}

Rata-rata akumulasi curahan waktu kerja wanita Peternak Itik di Desa Asam Peutik dapat lebih jelas dilihat pada Tabel 4.

Tabel 4. Rata-rata Akumulasi Curahan Waktu Kerja Wanita Peternak Itik di Desa Asam Peutik, Kecamatan Langsa Kota, Kota Langsa, 2020.

\begin{tabular}{|c|c|c|c|c|c|c|c|}
\hline \multirow[t]{2}{*}{$\mathrm{N}$} & \multirow{2}{*}{$\begin{array}{l}\text { Jenis } \\
\text { Pekerjaan }\end{array}$} & \multicolumn{5}{|c|}{ Curahan Waktu Kerja (Jam/Hari) } & \multirow{2}{*}{$\begin{array}{l}\%(24 \\
\text { Jam) }\end{array}$} \\
\hline & & $\begin{array}{l}\text { Mencari } \\
\text { Nafkah }\end{array}$ & Jumlah & Istirahat & Domestik & Sosial & \\
\hline 1 & $\begin{array}{l}\text { Peternak } \\
\text { Itik }\end{array}$ & 6,26 & 6,43 & 1,57 & 14,26 & 59,42 & 9,74 \\
\hline
\end{tabular}

Sumber: Data Primer (diolah) 
Berdasarkan Tabel 4 rata-rata curahan waktu kerja wanita Peternak Itik di Asam Peutik tertinggi adalah pada kegiatan mencari nafkah yaitu sebesar 6,43 jam/hari dan terendah adalah pada curahan waktu kerja untuk kegiatan sosial yaitu sebesar 1,57 jam/hari. Jumlah rata-rata Akumulasi curahan waktu kerja wanita Peternak Itik adalah sebesar 14,26 jam/hari dengan persentase 59,42\% dari kurun waktu 24 jam sementara 9,74 jam waktu digunakan untuk beristirahat. Rata-rata akumulatif curahan waktu kerja wanita Peternak Itik di Asam Peutik menunjukkan kegiatan yang memiliki curahan waktu kerja tertinggi adalah kegiatan mencari nafkah, terutama bagi wanita Peternak Itik yang tidak memiliki suami, hal ini menjadikan kegiatan mencari nafkah sebagai Peternak Itik di Desa Asam Peutik satu-satunya sumber pendapatan keluarga.

\section{Pendapatan Keluarga}

Rata-rata pendapatan keluarga wanita Peternak Itik di Desa Asam Peutik dapat dilihat pada Tabel 5.

Tabel 5. Rata-rata Pendapatan Keluarga Wanita Peternak Itik di Desa Asam Peutik, Kecamatan Langsa Kota, Kota Langsa, 2020.

\begin{tabular}{llllll}
\hline No & $\begin{array}{l}\text { Jenis } \\
\text { Pekerjaan }\end{array}$ & $\begin{array}{l}\text { Tingkat } \\
(\text { Rp/Bulan })\end{array}$ & Pendapatan & Keluarga & $\begin{array}{l}\text { Total Pendapatan } \\
\text { (Rp/Bulan) }\end{array}$ \\
\cline { 3 - 5 } & Suami & Istri & $\begin{array}{l}\text { Sumber } \\
\text { Lain }\end{array}$ & \\
\hline 1. & $\begin{array}{l}\text { Wanita } \\
\text { Peternak Itik }\end{array}$ & 1.280 .952 & 2.247 .619 & 114.286 & 3.642 .857 \\
\hline
\end{tabular}

Sumber : Data Primer (diolah)

Berdasarkan Tabel 5 rata-rata total pendapatan keluarga wanita Peternak Itik di Desa Asam Peutik adalah sebesar Rp.3.642.857,-/bulan. Rata-rata tingkat pendapatan tertinggi diperoleh dari pendapatan istri yaitu sebesar Rp. 2.247.619,/bulan dan terendah diperoleh dari pendapatan sumber lain yaitu sebesar Rp. 114.286,-/bulan. Hal ini dikarenakan pekerjaan suami dari wanita Peternak Itik tidak menetap setiap harinya seperti buruh bangunan, tukang becak, nelayan dan lain-lain. Keadaan perekonomian yang tidak menentu menjadikan wanita Peternak Itik ikut bahu-membahu dalam menignkatkan pendapatan keluarga agar semua kebutuahan keluarga tercukupi dengan baik.Sumber lain diperoleh dari salah satu anggota keluarga wanita Peternak Itik yakni anak dari wanita Peternak Itik tersebut. Pendapatan dari sumber lain berasal ddari anggota keluarga yang bekerja sebagai pelayan toko, pembuat kue dan lain-lain.

\section{Kontribusi Pendapatan}

Rata-rata kontribusi pendapatan ekonomi yang disumbangkan wanita Peternak Itik di Asam Peutik dapat lebih jelas dilihat pada Tabel 6. Berdasarkan Tabel 6 rata-rata kontribusi pendapatan ekonomi wanita Peternak Itik di Desa Asam Peutik adalah sebesar 63,28 \% /bulan. Kontribusi pendapatan wanita Peternak Itik di Asam Peutik terhadap pendapatan keluarga adalah tergolong tinggi yakni 
sebesar 63,28 \% lebih besar dibandingkan kontribusi pendapatan suami yaitu sebesar $33,22 \%$.

Tabel 6. Rata-rata Kontribusi Pendapatan Ekonomi Wanita Peternak Itik di Desa Asam Peutik, Kecamatan Langsa Kota, Kota Langsa, 2020.

\begin{tabular}{|c|c|c|c|c|}
\hline \multirow{2}{*}{ No } & \multirow{2}{*}{$\begin{array}{c}\text { Jenis Pekerjaan } \\
\text { Wanita }\end{array}$} & & & \\
\hline & & Suami & Istri & Sumber Lain \\
\hline 1 & Peternak Itik & 33,22 & 63,28 & 3,50 \\
\hline
\end{tabular}

Kontribusi Pendapatan Keluarga (\%/Bulan)

Sumber : Lampiran 8

Hal ini disebabkan sebagian besar penghasilan suami diperoleh dari bekerja sebagai buruh dan pekerjaan lain yang pendapatannya rendah selain itu juga ada beberapa sampel wanita Peternak Itik yang tidak memiliki suami sehingga kontribusi pendapatan wanita Peternak Itik menjadi satu-satunya sumbangan bagi pendapatan total keluarga. Selaras dengan hasil penelitian Amin, dkk (2016) yang menyatakan tenaga kerja wanita pada usaha emping melinjo rumahan di Desa Sukomangli Kecamatan Reban Kabupaten Batang memberikan kontribusi terhadap pendapatan keluarga, rata-rata sebesar 61,71 persen.

\section{KESIMPULAN DAN SARAN}

Dari hasil penelitian dapat disimpulkan rata-rata curahan waktu kerja domestik wanita Peternak Itik untuk kegiatan memasak dan mencuci sama yaitu sebesar 1,17 jam/hari sementara curahan waktu kerja tertinggi adalah pada kegiatan mengurus anak yaitu sebesar 2,71 jam/hari. Rata-rata curahan waktu kerja mencari nafkah adalah sebesar 6,43 jam/hari dengan persentase sebesar $26,79 \%$. Untuk curahan waktu kerja pada kegiatan domestik tertinggi yaitu pada kegiatan mengurus anak diikuti kegiatan membersihkan rumah, menyuci dan paling terendah adalah memasak. Kegiatan mengurus anak dimulai dari sebelum melakukan kegiatan mencari nafkah pada pagi hari dan setelah pulang. Kegiatan beternak itik di Desa Asam Peutik dimulai sejak pukul 04.30-10.00 WIB. Ratarata curahan waktu kerja kegiatan sosial tertinggi pada kegiatan pengajian yaitu sebesar 0,67 jam. Total pendapatan keluarga wanita peternak itik di Desa Asam Peutik adalah sebesar Rp.3.642.857,-/bulan. Rata-rata tingkat pendapatan tertinggi diperoleh dari pendapatan istri yaitu sebesar Rp. 2.247.619,-/bulan dan terendah diperoleh dari pendapatan sumber lain yaitu sebesar Rp. 114.286,/bulan. Kontribusi pendapatan wanita Peternak Itik di Asam Peutik terhadap pendapatan keluarga tergolong tinggi yakni sebesar 63,28 \% lebih besar dibandingkan kontribusi pendapatan suami yaitu sebesar $33,22 \%$.

\section{DAFTAR PUSTAKA}

Ahmadi. 2012. Sarjana Membangun Desa Turut Memberdayakan Usaha Peternakan Rakyat. Fakultas Peternakan. Universitas Diponegoro. Semarang. 
Ambador, J. 2008. CSR (Corporate Social Responsibility) Dalam Praktek Di Indonesia. Kompas Gramedia, Jakarta.

Amin, M. N, S Supardi, S.N Awami. 2016. Kontribusi Tenaga Kerja Wanita Pada Usaha Emping Melinjo Terhadap Pendapatan Keluarga (Studi Kasus di Desa Sukomangli Kecamatan Reban Kabupaten Batang). Jurnal Mediagro. Vol. 12. No. 2. Hal 26-38. Fakultas Pertanian. Universitas Wahid Hasyim. Semarang.

Amrullah, I. K. 2004. Nutrisi Unggas Petelur. Cetakan ke 3. Lembaga Satu Gunungbudi, Bogor.

Andarwati, S. dan Guntoro, B. 2007. Analisis Sikap Peternak Ayam Ras Terhadap Aspek Lingkungan dan Ekonomi di Kabupaten Bantul, Buletin Peternakan, Fakultas Peternakan UGM. Yogyakarta.

Anindyasari, D., A. Setiadi, Dan T. Ekowati. 2015. Analisis Pendapatan Peternak Sapi Perah di Kecamatan Banyumanik, Kecamatan Getasan dan Kecamatan Cepogo. Mediagro. 11 (2) : 22-33.

Ardi, A. 2016. Keragaman Sifat Kuantitatif Itik Pitalah di Kelompok Tani Syariah Terpadu Nagari Batipuh Baruah Kecamatan Batipuh Kabupaten Tanah Datar. Fakultas Peternakan Universitas Andalas. Badan Penerbit Universitas Andalas. Padang.

Azwar, S. (2005). Sikap Manusia: Teori dan Pengukurannya. Yogyakarta: Pustaka Pelajar.

Basriwijaya, K. M. Z, HS Maryoni. 2017. Potensi dan Kontribusi Sumber Daya Manusia terhadap Peningkatan Pendapatan Keluarga. Cano Ekonomos 6 (2), 101-104.

Basriwijaya, K. M. Z, Sumekar, W. Ekowati, T. Sunarti, D, 2019. Influence of physical and social factors of livestock on duck farmers' income and regional development: A case of Rokan Hulu regency, Riau indonesia International Journal of Recent Technology and Engineering 8 (9) 10211027.

Bloom, Benyamin. 1908. Psikologi Pendidikan. Jakarta: PT Gramedia.

Gumilar, R. 2005. Memahami Metode Kualitatif. Makara Seri Sosial Humaniora, 9 (2), 57-65. 
Gusmaniar. 2013. Kontribusi Pendapatan Wanita Peternak Kelinci terhadap Total Pendapatan Keluarga di Kelurahan Salokaraja Kecamatan Lalabata Kabupaten Soppeng. Universitas Hasanuddin, Makasar.

Lutviani, Vina, S. Wahyuningsih, S.N. Awami. 2020. Kontribusi Tenaga Kerja Wanita Pemetik Teh (Camellia sinensis (L.) Kuntze) Terhadap Pendapatan Keluarga (Studi Kasus di PT Pagilaran Desa Keteleng Kecamatan Blado Kabupaten Batang). Jurnal Penelitian Agrisamudra. Vol. 7 No 1, Juni. Fakultas Pertanian Universitas Samudra. Aceh.

Mardiana, D. 2004. Profil Wanita Pengolah Ikan di Desa Blanakan Kecamatan Blanakan Kabupaten Subang Jawa Barat. Program Studi Manajemen Bisnis Kelautan. Fakultas Kelautan dan Ilmu Kelautan. Institut Pertanian Bogor. Bogor.

Wiratha, I Made. 2006. Metode Penelitian Sosial Ekonomi. Yogyakarta. Andi. 